\title{
Architectural design enhancement of gardens/parks in Yerevan
}

\author{
Martin Harutyunyan ${ }^{1 *}$ \\ ${ }^{1}$ Institute of Arts of National Academy of Sciences of Armenia, Armenia
}

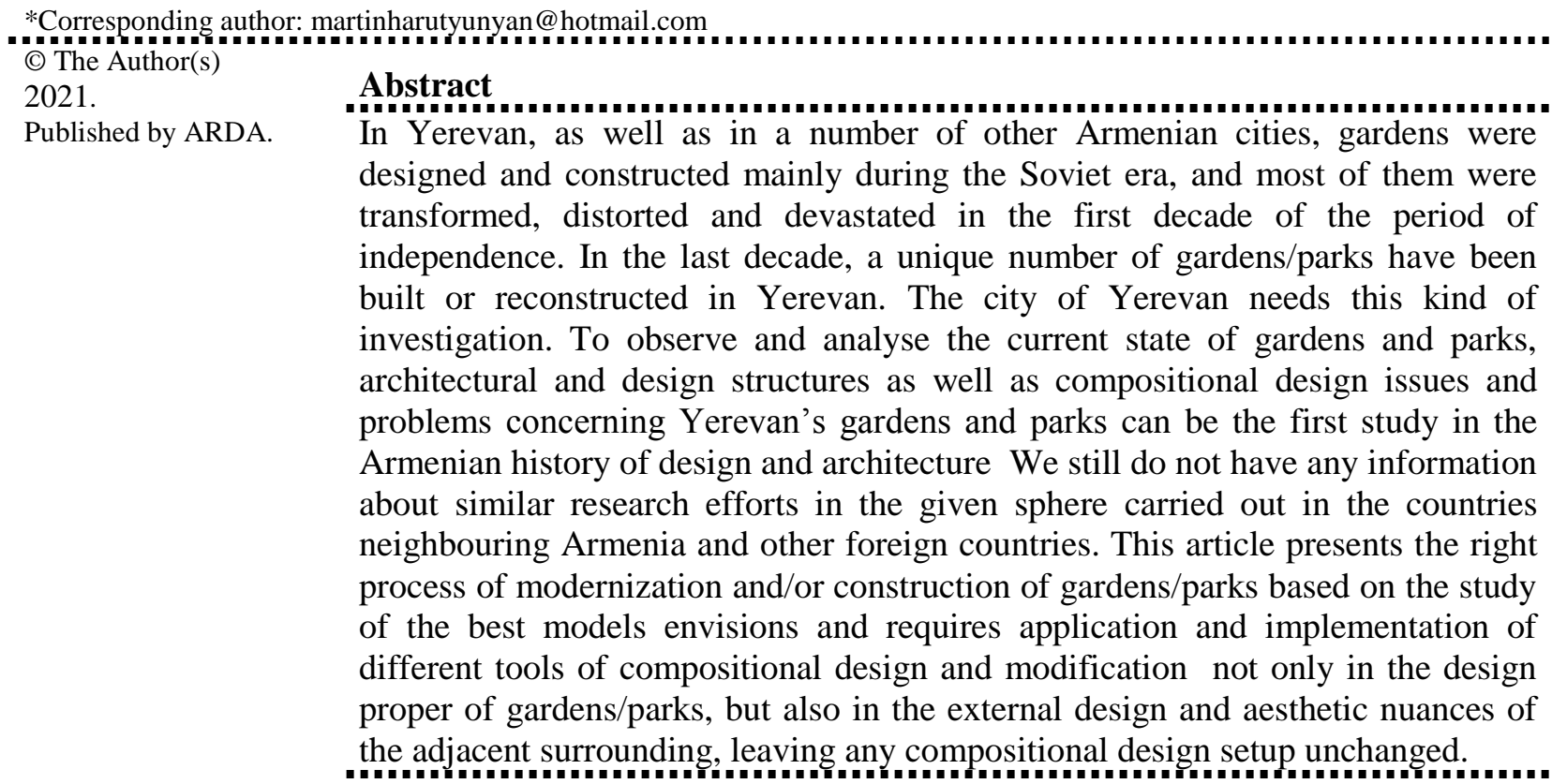

Keywords: Yerevan, Garden, Park, Design, Architecture, Reconstruction, Green architecture

\section{Introduction}

Why is landscape or "green" architecture important? "Green" architecture is the way positioned to respond to the urgent issues of our time, including mitigating climate change and contributing to the sustainability of both individual sites and cities as a whole. It is still more important for many post-Soviet cities where all old parks and gardens have been destroyed. In Yerevan, as well as in a number of other Armenian cities, gardens were designed and constructed mainly during the Soviet era, and most of them were transformed, distorted and devastated in the first decade of the period of independence. This period witnessed the emergence and development of small and medium-size enterprises. A great number of small businesses and private enterprises operated in stores, kiosks, commercial buildings, small markets and fairs. This was the result of the tough social and economic situation of the period. People used to set up commercial buildings in accordance with their wishes, financial assets and capabilities to obtain spaces and premises - entrances of residential buildings, basements and first floor apartments were transformed into stores or other commercial spaces; commercial areas, kiosks or simply residential buildings were set up in the adjacent gardens of main streets. All these constructions deformed and marred the architectural and aesthetic appearance and composition of many Armenian cities. Among this type of architectural problems were also a number of architecture-design and compositional distortions of gardens/parks when the latter were simply turned into restaurant complexes, commercial or residential buildings. Unlike other architectural problems affecting urban planning and city landscape, the distortion of the parks and the decline of their number have directly affected the city's ecology and the health of its residents, resulting in escalation of a number of life-threatening diseases [1].

This work is licensed under a Creative Commons Attribution License (https://creativecommons.org/licenses/by/4.0/) that allows others to share and adapt the material for any purpose (even commercially), in any medium with an acknowledgement of the work's authorship and initial publication in this journal. 


\section{Analysis of parks}

Armenia is still a developing country today, and there are many unresolved problems in many spheres. However, today some positive changes are already noticeable in the area of gardens/parks planningdevelopment and their design and architectural composition defects review. The scrupulous study of each deteriorated structure, the right options and attitudes directed at restoration and renovation of the city gardens/parks will facilitate the implementation of architectural and decorative design initiatives, will boost the country's monotonous cultural routine, and will increase the involvement of the public in the aesthetics of external design. Interestingly enough, unaesthetic attitudes, non-professional approaches towards parks and gardens and their design have been observed not only in Armenia but also in other Post Soviet states and cities. Yerevan's parks and gardens, presenting architectural, cultural and ecological value, are not only used inadequately, but undergo intense transformation each year. Subsequently, they are replaced by modern structures which are incomplete from the point of view of compositional and design-oriented solutions. This replacement not only destroys the historical-cultural heritage preserved in the gardens/parks and urban planning, but also makes an unaesthetic impression on those who view them. The result of such enormous architectural deformation is that cities lose their former look and the beautiful decorative and design elements typical of them. It is a fact that over the past decade a number of green areas have been set up in Yerevan, many parks and gardens have been reconstructed professionally - the Lover's Park [2], as seen in Fig.1, and Yerevan-2800 Park [3] as seen in Fig.2, for example.

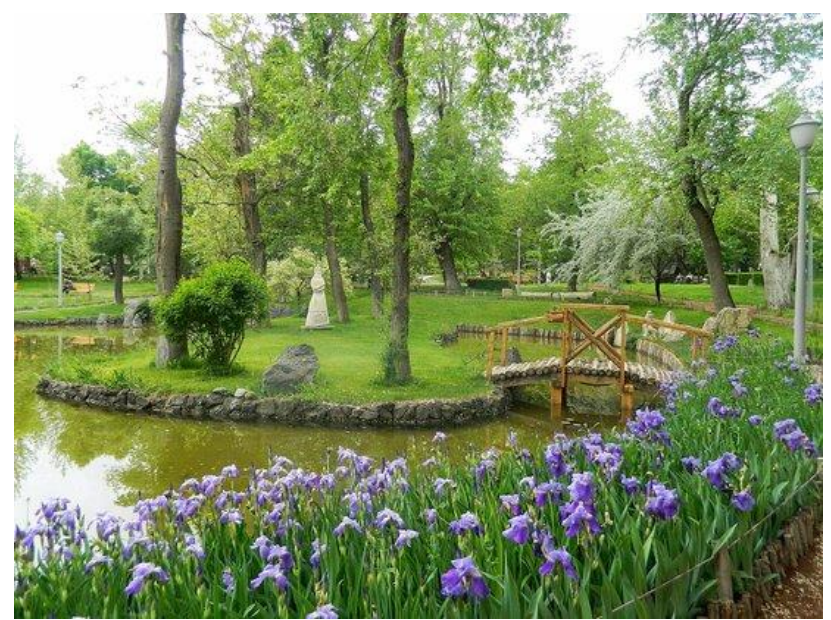

Figure 1. The Lover's park

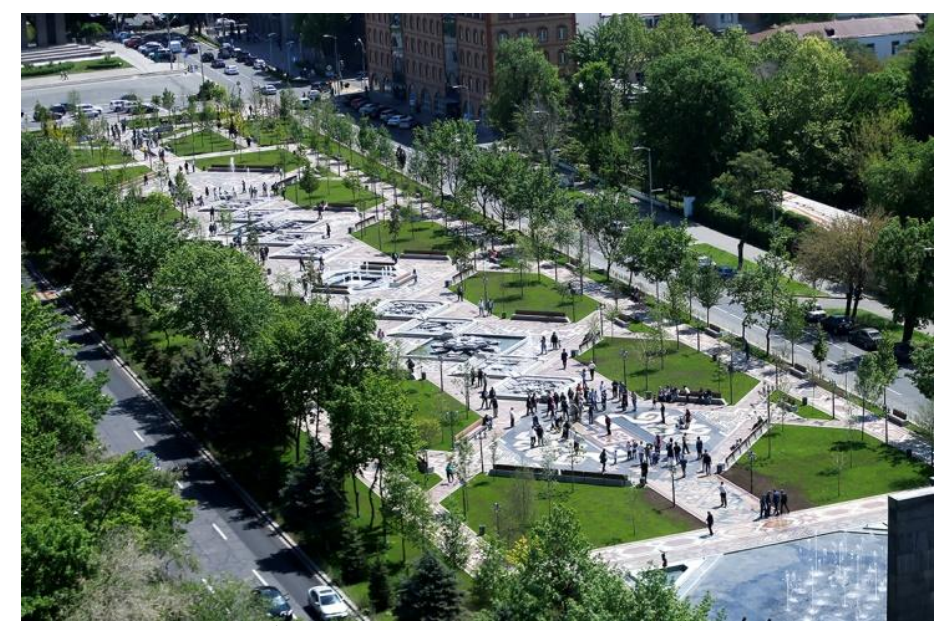

Figure 2. Yerevan-2800 park

However, there are parks/gardens with much unqualified, unprofessional work: no architects, designers and landscape or urban design professionals have been involved in such work (see Fig. 3, Fig. 4, Fig. 5, Fig. 6).

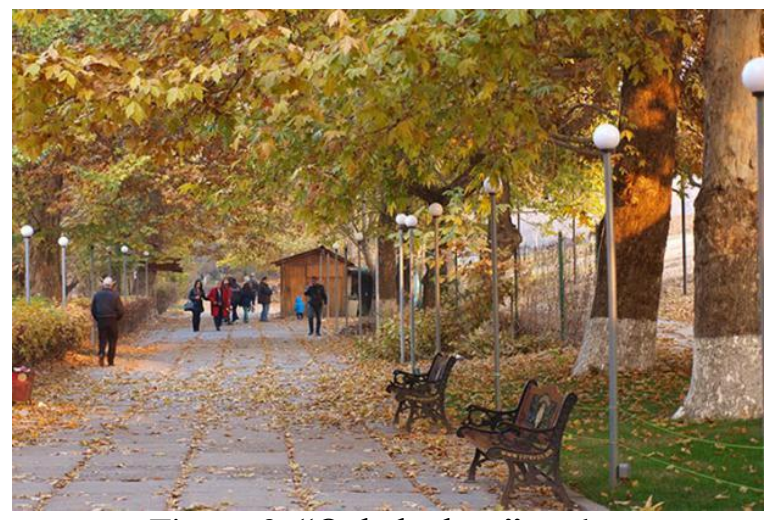

Figure 3. "Oghakadzev" park

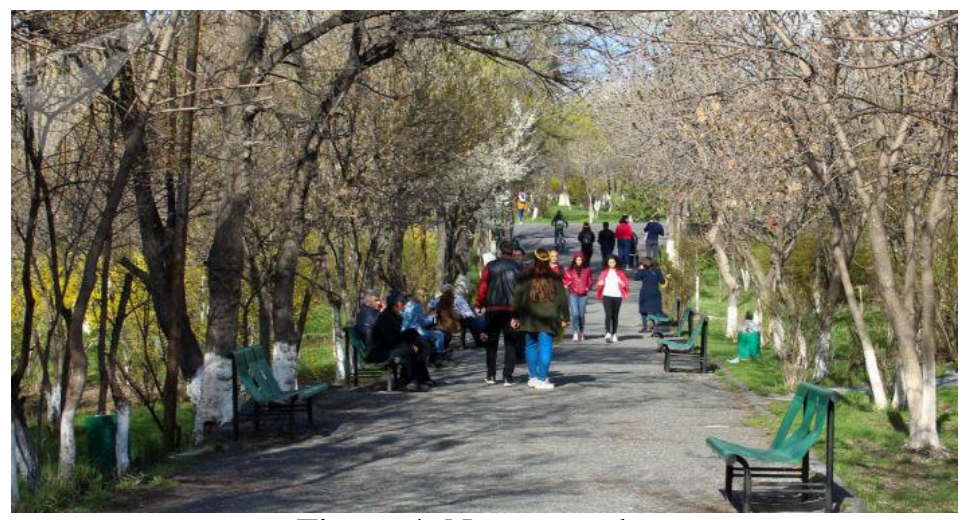

Figure 4. Nansen park 


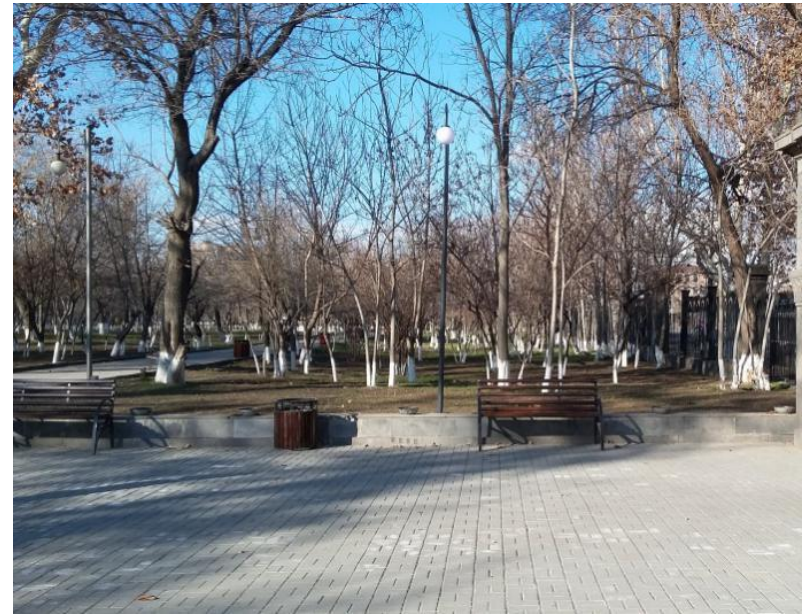

Figure 5. Komitas park

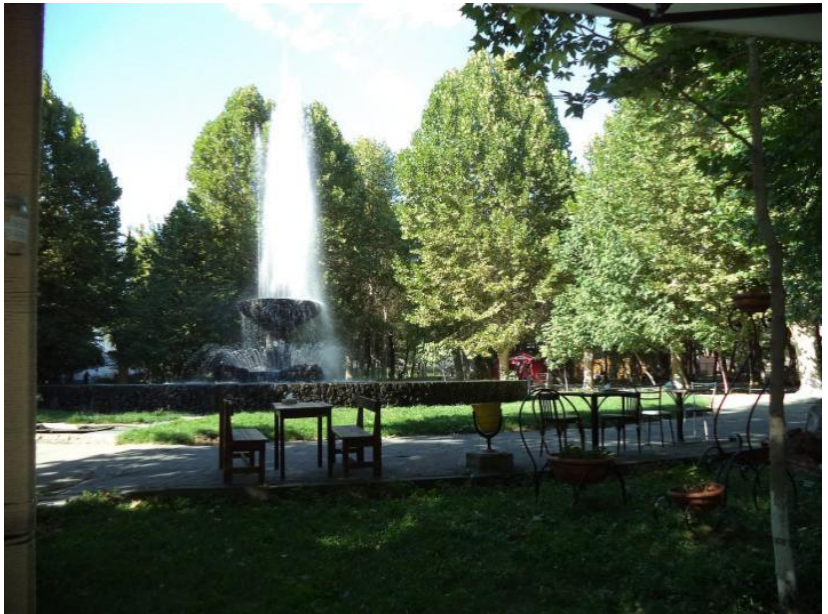

Figure 6. English park

The modern world, where new architectural and design spheres are developing daily, not only focuses greatly on design innovations and aesthetics, but also considers it very important to create an ecologically positive environment through professional redesigning, restructuring and reconstructing of gardens/parks.

In general the garden design is the art and process of designing and creating plans for layout and planting of gardens and landscapes. Garden design may be done by the garden owners themselves, or by professionals of varying levels of experience and expertise. Most professional garden designers have some training in horticulture and the principles of design. Amateur gardeners may also attain a high level of experience from extensive hours working in their own gardens, through casual study, serious study in Master Gardener Programs, or by joining gardening clubs. To create a garden design is not only the landscape or "green" design but it is also a "design thinking", architectural education, design theory and aesthetics.

The city of Yerevan needs observation and investigation of all past and present gardens. There is no collection of information from documentaries, archives, and professional web pages including the present situation of Yerevan's gardens/parks architecture or design situation.

The problem of the design and composition of the gardens/parks of Yerevan and the possible options for professional improvement of them also requires research of the world-renowned gardens/parks design materials, architectural compositions, landscape designs and other documentary data. The best samples of professional garden designs are The garden of cosmic speculation in Dumfries, Scotland Fig. 7, Villa Celle Gardens in Pistoia, Italy Fig. 8, Eden garden projects in Cornwall, Great Britain Fig. 9, Les Jardins de Marqueyssac in Dordogne, France Fig. 10, Gardens of Peterhof in St. Petersburg, Russia Fig. 11, Boboli gardens in Florence, Italy Fig. 12, Central park in New York, USA Fig. 13, Mirabell gardens in Salzburg, Austria Fig. 14, Hyde park in London, Great Britain Fig. 15, Jardin du Luxembourg in Paris, France Fig. 16.

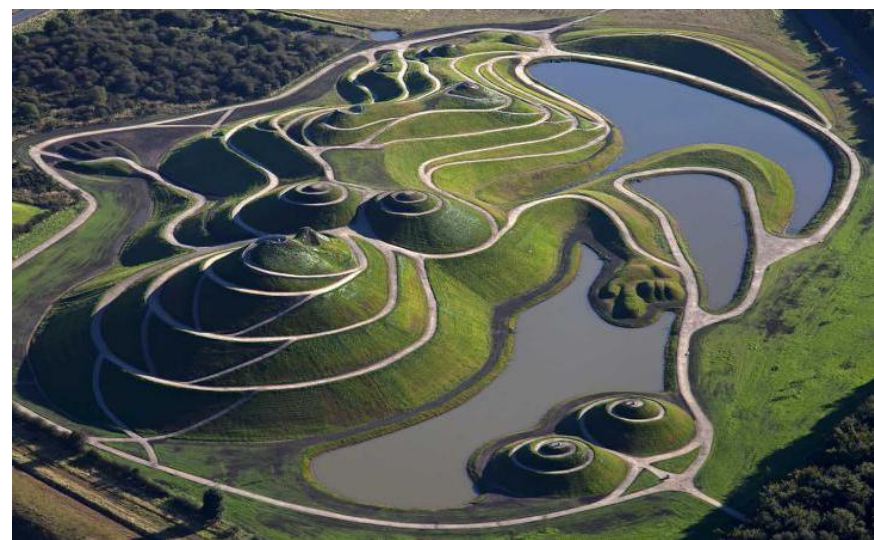

Figure 7. The garden of cosmic speculation (Dumfries, Scotland

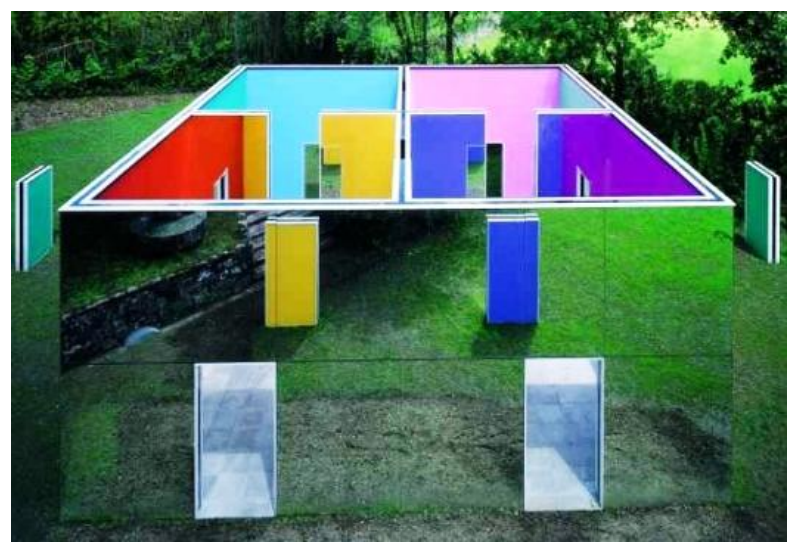

Figure 8. Villa Celle Gardens Pistoia, Italy 


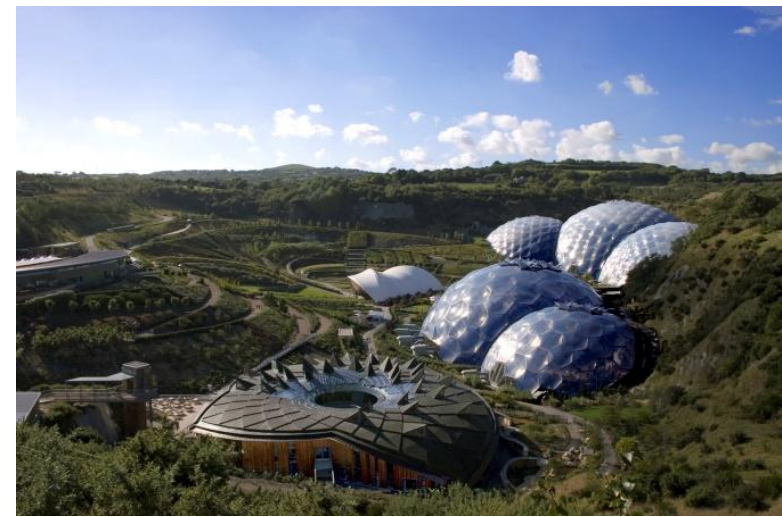

Figure 9. Eden garden projects (Cornwall, Great Britain)

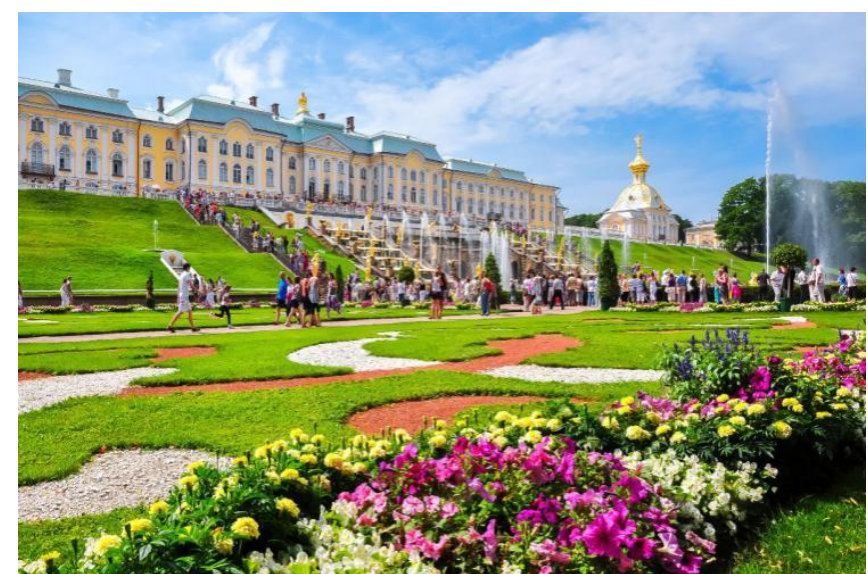

Figure 11. Gardens of Peterhof (St. Petersburg, Russia)

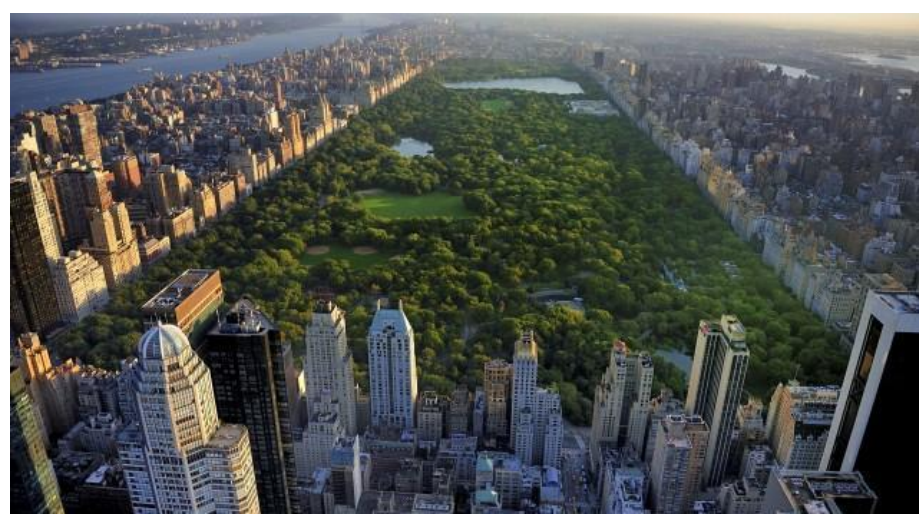

Figure 13. Central park (New York, USA)

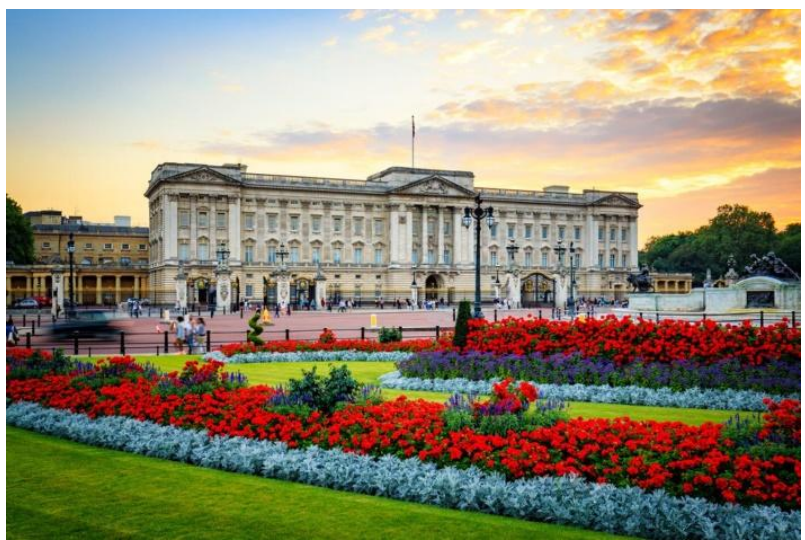

Figure 15. Hyde park (London, Great Britain)

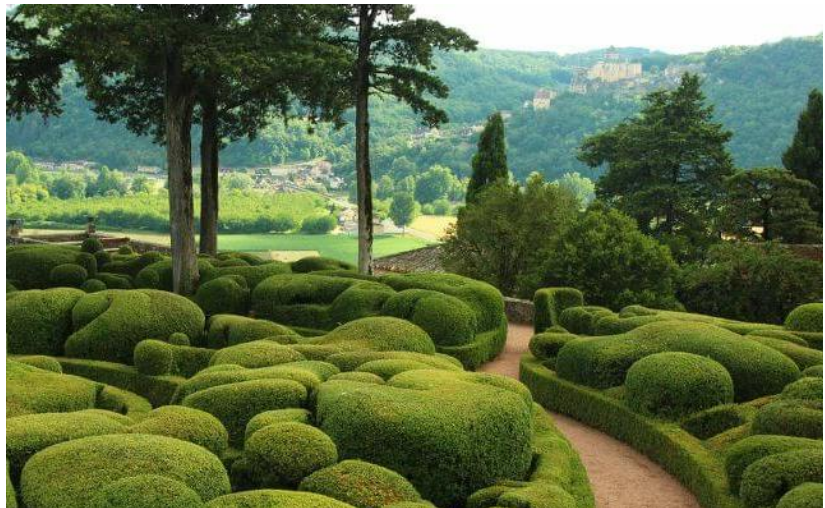

Figure 10. Les Jardins de Marqueyssac (Dordogne, France)

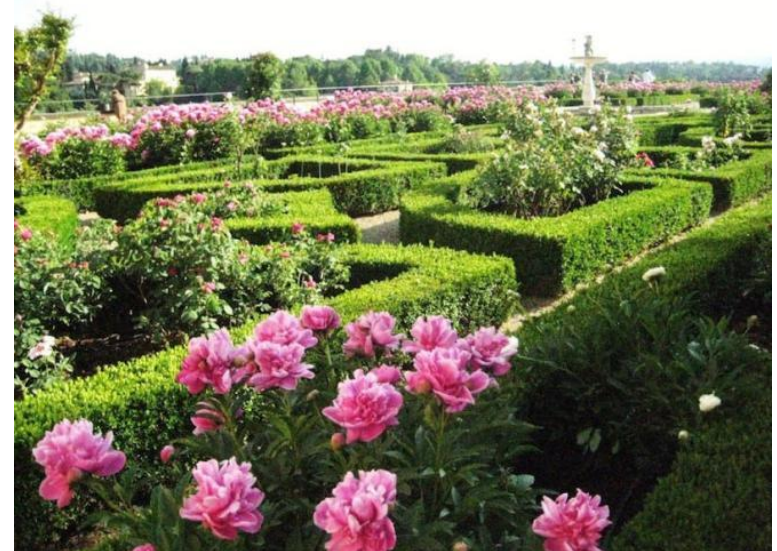

Figure 12. Boboli gardens (Florence, Italy)

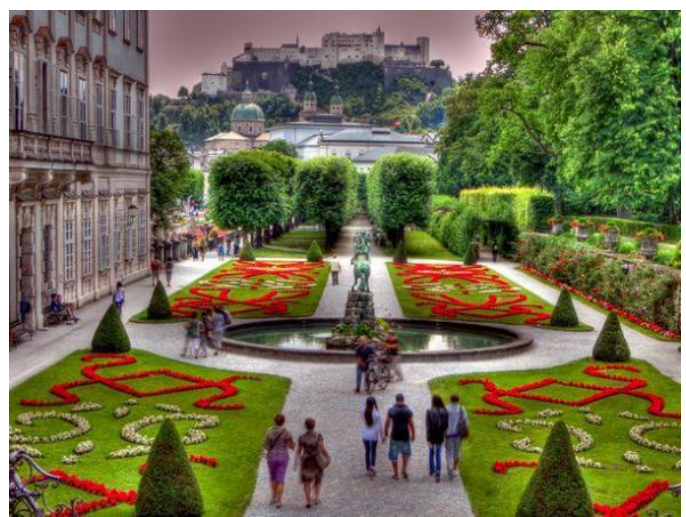

Figure 14. Mirabell gardens (Salzburg, Austria)

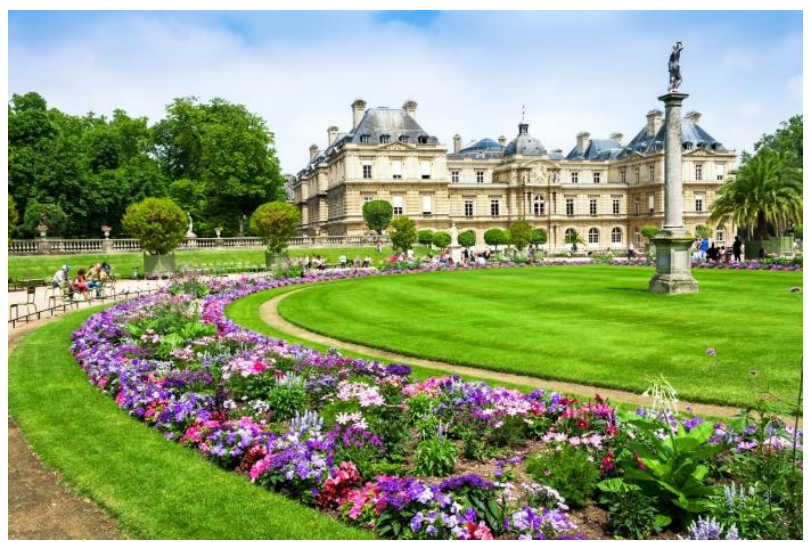

Figure 16. Jardin du Luxembourg (Paris, France) 
Examining in detail (virtually) the above-mentioned gardens and their architectural designs we have found out that, to develop Yerevan's gardens and parks, it is urgent to:

1. make a list of past and present gardens/parks (including the reconstructed ones) of the city of Yerevan;

2. include in the list those gardens/parks, in which there are architectural or design distortions;

3. present a documentary analysis of the current situation of several parks/gardens in the selected areas/regions;

4. find modern design solutions aimed at eliminating compositional and aesthetic defects in the Yerevan gardens/parks using contemporary methodology;

5. study the best examples of famous French, Italian, Russian, American, Austrian, and Chinese gardens, their current situation, architectural structure, compositional solutions and landscape designs;

6. collect documentary data in museums, archives, and research institutions on a given garden/park, evaluate their architectural and design peculiarities;

7. work out and offer possible design solutions and aesthetic principles for Yerevan's gardens based on the best examples of famous gardens in foreign cities;

8. develop clear professional rules and norms including possible options for improving orchard/garden/park design considering architectural design practiced internationally.

Today garden and park renovations projects are more relevant than ever. The absolute majority of the Yerevan gardens/parks subject to study in the present/future, have never been rebuilt after the Soviet era, hence they can actually be modernized and adapted to modern landscape design requirements. At the same time, they can undergo regenerative transformation that will not only make it possible to preserve the architectural and decorative value of the given heritage, but will give new life and ae-sthetic view to the city of Yerevan at large, simultaneously addressing air pollution and environmental issues. It is an indisputable fact that in all periods of historical development of a city, gardens, parks and botanical gardens have been built (based on classical and modern architecture and design solutions) and transformed (their landscapes and compositional structures). The problem is that the new ones should not replace the old ones at the expense of a complete destruction of the latter and distortion of the historical layer of the given city.

The right process of modernization and/or construction of gardens/parks based on the study of the best models envisions and requires application and implementation of different tools of compositional design and modification not only in the design proper of gardens/parks, but also in the external design and aesthetic nuances of the adjacent surrounding, leaving any compositional design setup unchanged.

The city of Yerevan needs this kind of investigation. To observe and analyse the current state of gardens and parks, architectural and design structures as well as compositional design issues and problems concerning Yerevan's gardens and parks can be the first study in the Armenian history of design and architecture We still do not have any information about similar research efforts in the given sphere carried out in the countries neighbouring Armenia and other foreign countries.

Research must be based on on-site surveys in Yerevan and other foreign cities (research in 1-2 European cities is highly recommended). The realization of the project needs to have visits to all the parks/gardens of Yerevan and numerous other parks and gardens located at least in two neighboring/foreign cities: Tbilisi, St. Petersburg, Moscow, Paris, Lyon, London, Vienna, Salzburg, New York and Beijing. Virtual online or library research will focus on materials referring to gardens/parks located in other, more remote cities. Investigation and data research will be carried out in museums, archives and other research institutions. Only this kind of step-by-step research can solve the gardens/parks architecture and design problems of Yerevan. Hopefully, this will be done soon.

\section{Conclusion}

Reconstruction of parks and gardens in Yerevan needs immediate implementation. They should be implemented on the basis of specific professional analysis and suggestions of specialists - designers, architects, builders. It is necessary to study the international experience by studying the experience of reconstruction of famous parks in foreign cities. Unfortunately, such a reconstruction program has never been implemented in Yerevan, so the implementation of this program will give a new impulse to the architectural and design style of a number of cities in Armenia, urban development and the development of green areas. 


\section{References}

[1] Martin Harutyunyan, "The possible application of modern stage technologies in the reconstruction of Armenian auditorial halls with scenic sections", “Antares" Holding, pp. 5-7, 2016.

[2] Project, B. G. (n.d.). Boghossian garden official webpage. Retrieved 3 10, 2020, Available at: https://www.bg.am/index.php?lang=1\&id=4

[3] "Yerevan inaugurates stunning new park in downtown", Retrieved 3 10, 2020, Available at: https://armenpress.am/eng/news/974302.html, 